\title{
Environmental planning and management of air quality: the case of Mexicali, Baja California, Mexico
}

\author{
E. Corona-Zambrano \& R. Rojas-Caldelas \\ Faculty of Architecture, Autonomous University of Baja California, \\ Mexico
}

\begin{abstract}
There is a worldwide increase in the number of people living in cities. As a consequence, this brings a number of social, economic and environmental problems relating to a decline of the environment and the quality of life. Air quality stands out among the problems of medium and large cities, mainly due to the increase of industrial activity, urban mobility, mobility from one city to another and of urbanization levels. That is why human settlements face important challenges in order to lower the levels of emission of pollutants into the atmosphere that are considered aggressive and hazardous for the built up environment, ecosystem and human health. In this context, the city of Mexicali stands out in the country for the problems relating to air quality it faces, mainly pollutants such as $\mathrm{CO}, \mathrm{PM} 10$ and $\mathrm{O}_{3}$. This report presents the results of research which has the purpose of designing a system of indicators for the study of air quality in the city of Mexicali, based on the pressure-state-response (PSR) model from OECD. This system is complemented with information of other urban variables, as well as population, traffic infrastructure, transportation, and land uses among others, trying to identify which strategies need to be applied in the city. Lastly, an urban assessment about pollution and strategies that can be applied in different fields involved in air quality is presented.
\end{abstract}

Keywords: urban air quality, environmental management of air quality, atmospheric pollution, sustainable urban planning. 


\section{Introduction}

The management and strategies applied in Mexico to protect health and decrease the pollution levels in human settlements, has taken place through establishing quality regulations for each air pollutant. More recently, monitoring has been established in the main cities and the programs to improve air quality known as PROAIRES, which include concrete measures to decrease and control pollutant emissions. A characteristic of these programs is that government authorities participate (federal, state and local).

However, industrial regulations are inefficient (SEMARNAP [11]), through the urban scope, planning is still focused on land use, reducing the environmental dimension, along with the scarce information available for citizens about the industrialization and urbanization phenomenon and their impact on health, specifically on respiratory diseases.

The previous gets complicated with the actual trend, like the worldwide increase of the urbanization process in developing countries. According to United Nations (UNEP [12]), currently almost half of the world population lives in urban areas, expecting it to be $90 \%$ by the year 2030 . In Mexico, $75 \%$ of its total population live in urban areas, where cities like Chihuahua, Aguascalientes, Mérida, Hermosillo and Mexicali among others which have around 500000 to 1'000 000 million inhabitants, are part of the main urban system, and considered also strategic cities of economic and demographic corridors important in the region.

Based on that, this report has a double purpose; on the one side it shows the problem of air quality in Mexicali through state indicators and their relationship with land uses in the city, and on the other side to show the strategies used to decrease pollution from the point of view of different agencies. Lastly, to present some strategies dealing with urban planning and management topics to tackle air quality problems.

In the case of Mexicali, the economy of the city-region is supported mainly by the services sector, which employs $54.48 \%$ of the working population, while the industrial sector employs $35.46 \%$ and the primary sector a $10.06 \%$ (XVIII City Council of Mexicali-IMIP [2]), where agriculture and geothermal electric production as well as the sands and gravel extraction for construction work. These activities show certain patterns of territorial distribution and at the same time show a concentration of pollutants which affect the health of the inhabitants of the city. Mexicali is located north in the Mexican Republic in the state of Baja California $\left(32^{\circ} 40^{\prime} \mathrm{N}, 115^{\circ} 27^{\prime} \mathrm{W}\right)$, adjoins north with the state of California, USA (Figure1), and it is known for its extreme dry weather and extreme temperatures. During summer temperature rises up to $54^{\circ} \mathrm{C}$ and in winter to $7^{\circ} \mathrm{C}$. The average precipitation is $54.2 \mathrm{~mm}$; the city is located in an arid region named Lower Colorado Delta belonging to the physiographic region of the Sonora desert. Also, the Colorado Delta has supported the agricultural areas from both sides of the border, along with its problems in air pollution for agricultural fires and spraying crops. On the other hand, car ownership is high, with one vehicle for every three inhabitants in the city of Mexicali. In the same way, the manufacturing industry 
has always been one of the motors of the local economy, activities that have worsen air quality, an issue that due to its local impact has become of binational concern.

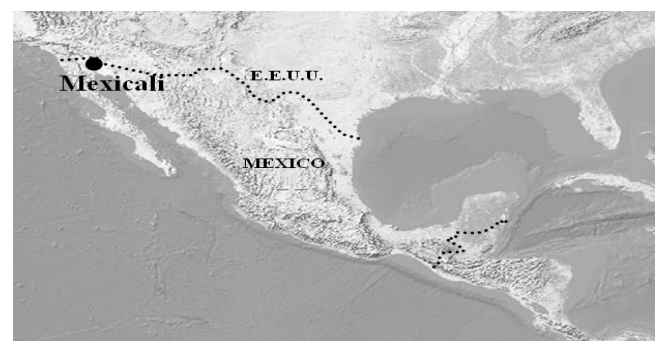

Figure 1: Location of Mexicali.

\section{Methods}

The assessment of air quality was made through the interpretation of the state indicators of environmental concentration of criteria pollutants recorded by the local monitoring system, composed by 6 stations located in the city, from which 4 monitor Ozone $\left(\mathrm{O}_{3}\right)$, Carbon Monoxide (CO), Sulfur Dioxide $\left(\mathrm{SO}_{2}\right)$, Nitrogen Dioxide $\left(\mathrm{NO}_{2}\right)$, and Particulate Material (PM10). In the case of Progreso and CONALEP stations, they only measure PM10, CBTIS station stopped working to be relocated south of the city in 2005, under the name Campestre. The monitoring project derived from an agreement between United States and Mexico governments through the Border XXI Program, which later became Border 2012 Program. Access to such information was through the Air Quality System database (AQS) 1997-2005 (AQS-UABC [1]) from the environmental protection agency (EPA) from the United States. For this case and in order to simplify the management of information, measuring of air quality was made by the number of days in which the respective standard was violated. To determine the characteristics of the immediate environment around the stations, an analysis of the land uses was made within a range of 1,500 meters, using the geographic information system Mapinfo vr. 7.8. For the proposed strategies, the base documents were checked and authorities in charge of the programs were interviewed.

\section{Results}

\subsection{Air quality in Mexicali}

Monitoring stations that integrate the local monitoring system are generally located inside the facilities of a school or in a public sector's building like the public health center of Progreso residential development. The urban features in land uses vary according to location (Figure 2). 


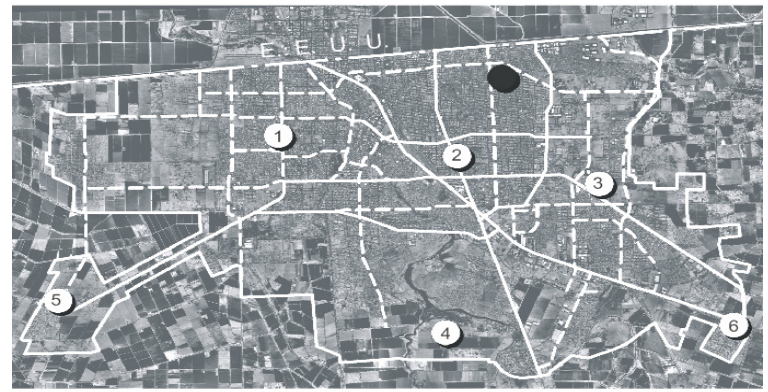

COBACH

UABC

ITM

Campestre

Progreso

CONALEP

CBATIS

Figure 2: $\quad$ Monitoring stations.

The main causes of air pollution come from energy production, motor vehicles, industry, open dumps (sanitary landfills now) dust storms which are very characteristic in the region, car traffic on unpaved roads, as well as crops burning on both sides of the border (Mendoza, et al., [6]; SEMARNAP [10]).

Results obtained from monitoring between 1997 and 2005, in the city of Mexicali show the dynamics of the city regarding the economic activities that support it and the environmental conditions related to its geographic location. Current data generated by the monitoring system match with previous reports made in 1997 and 1998 by SEMARNAP [10], where the main problem seemed to be PM10 particles, $\mathrm{CO}$ and $\mathrm{O}_{3}$ pollutants which mainly concentrated in COBACH, Progreso, CBTIS and UABC stations. (SEMARNAP [10]). However, data from 2005 reports a significant decrease even though currently levels of concentration of these exceed permissible levels of PM10 and $\mathrm{O}_{3}$.

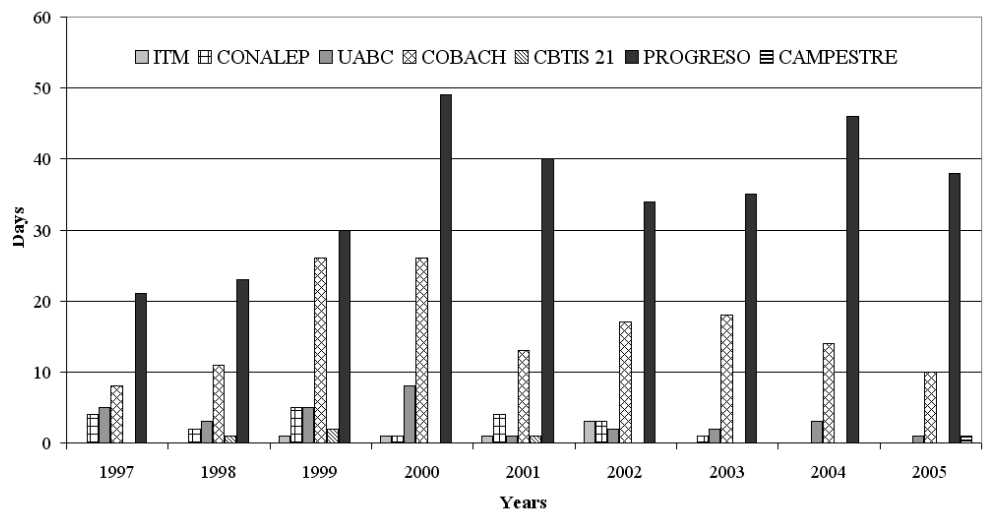

Figure 3: $\quad$ Number of days above the PM10 standard for 1997-2005.

In the case of PM10, a rising tendency from 1997 to 2000 for all the stations can be observed, reverting from 2000 to 2005 except for Progreso and COBACH stations, which currently exceed the corresponding quality standard. This is because these stations are located in the periphery of the city, where due to the 
low urbanization levels, traffic dust of unpaved roads, smoke from burning crops or derelict lands eroded by wind affect productive agricultural areas. The case of UABC station presents an exception, for being in an area of good urbanization, and a lower percentage of unpaved roads, a case that would be necessary to study in greater detail (figure 3).

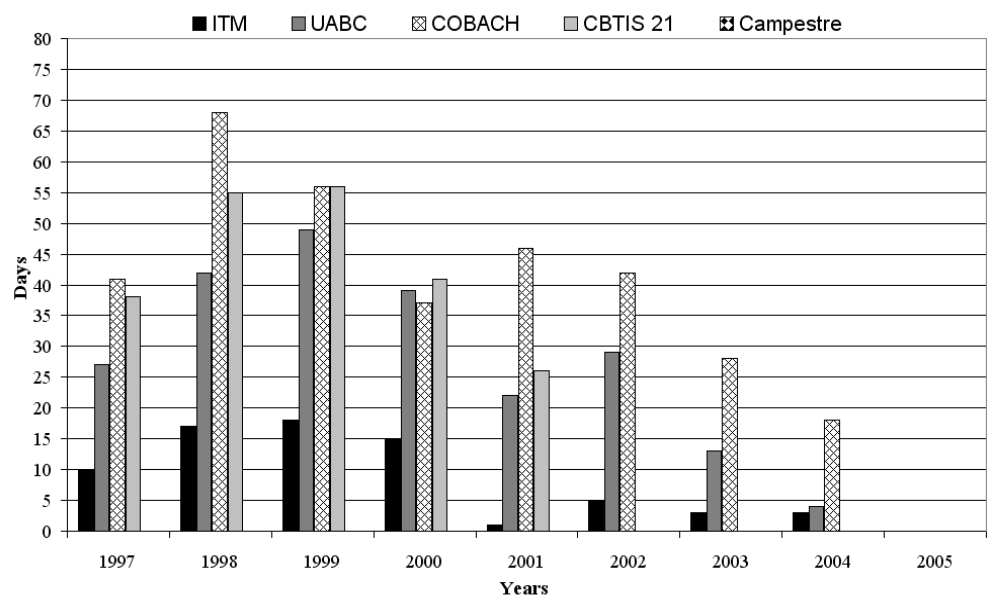

Figure 4: $\quad$ Number of days above the CO standard for 1997-2005.

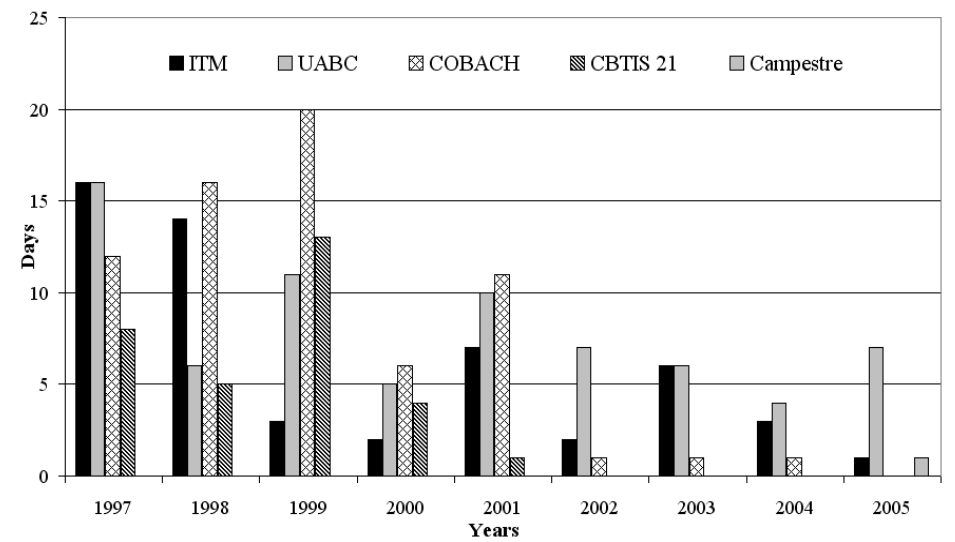

Figure 5: $\quad$ Number of days above the $\mathrm{O}_{3}$ standard for 1997-2005.

The $\mathrm{CO}$ for the analysis period shows a rising increase in the first three years, to decrease considerably and disappear in 2005. Although during this period stations like $\mathrm{COBACH}, \mathrm{UABC}$ and Campestre reported violations to the standard also but with a smaller number of days that year. During 2005 no more violations to the standard were registered (figure 4). 
$\mathrm{O}_{3}$ pollutant shows a general trend to decrease on most of the stations, despite its recovery in 1999 and 2001, by 2005 the number of violations to the standard decreased considerably. The presence of $\mathrm{O}_{3}$ continues on $\mathrm{UABC}, \mathrm{COBACH}$ and ITM stations, the last two continued exceeding the standard during 2005, though in a lower proportion. These stations represent mostly urban areas, with moderated to high population densities with concentration groups of urban public services of urban and regional importance, or industrial activities that involve great volume of traffic caused by the transportation of people and goods in the city (Figure 5).

\subsection{Implemented actions}

As an answer to air pollution problems in Mexicali, during 2000 and 2005 programs and actions were put into practice by different authorities and levels of the government, mostly the Ecology and Environment sector, like the ones made by the federal government for the improvement of air quality in Mexicali 20002005 (SEMARNAP [10]), trying to reduce the emissions of different pollutants that exceeded the standard. Strategies were aimed toward: vehicles, urban management and transportation, ecology recovery research and national agreements, from which 27 actions resulted.

According to the 2006 results only 5 specific actions were put into practice (Gordillo [3]; IIS-JUEBC [4]; Paez [8]), among these were: the transference of the monitoring net by the United States, who financed and operated it at first; the Integrated Pavement and Air Quality Program (PIPCA), that worked during 2003-2004, improving the levels of urbanization with the pavement work that benefited about 20 residential areas from the city, with a total surface of 214 hectares. Integrated study on public transportation and its improvement, suggests replacing a part of the fleet with new and modern buses; and the creation of a system of automated red-light on the most important roads in the city; environmental culture and city forestry, this program is operated in elementary school and recreational areas; vehicles, on this topic, the implementation of the program of vehicle checking, oriented to emission control that public and private transportation cause, a project which by 2006 was being elaborated and subject to approval by the city council.

\section{Discussion}

A series of strategies and actions instrumented to tackle the air pollution problem from the point of view of the Environment and natural resources department have been commented. However management of air quality has not been integrated to the urban local planning, neither an integral planning that joins other sectors which would need to be planned together to help solve the problems of pollution (Leitmann [5]; Mitchell [7]). It is necessary to remember that air quality is also competence of regional urban planning, because several situations may be prevented, avoided or minimized using urban and environmental planning instruments that offer a national, state and municipal legal framework. 
It is also clear that Mexicali presents problems of scarce planning or no planning at all, related to topics such as the growing number of vehicles, most of them imported from United States whose characteristics do not comply with the environmental quality standards; the public transportation that covers one third of the population; pavement work necessary for almost $60 \%$ of the streets in the city; industrial development that consumes $50 \%$ of the electric energy that is produced and that in terms of users it represents 1.14\% (Rojas [9]). Added to all of this, there are no local codes and institutions are not capable to control the banks of material around the city. Incompatible mixed land uses of residential and industrial developments, places for disposal of solid wastes and hazardous wastes. Agricultural land that have become derelict and plots of land that lack vegetation and get eroded, and with a deficit of $49.9 \%$ of green areas in the city (XVIII City Council of Mexicali-IMIP [2]).

Previous information shows that even though it is true that implementation of programs partially successful like pavement of roads, transportation and intelligent red-lights have contributed to reduce pollutants significantly such as $\mathrm{CO}$ and in less degree PM10 and $\mathrm{O}_{3}$, it has not been enough to keep under the standard these air pollutants with the urban and environmental characteristics that prevail in the area of influence of the monitoring stations.

It is important to note that in the case of industry, even though the levels of $\mathrm{NO}_{2}$ and $\mathrm{SO}_{2}$ have not presented violation to the standard since 2003. From the point of view of preventing environmental pollution also, it is necessary to consider the importance of this sector in the economic development, because if the trend to increase the number of industries planned for the industrial project of binational impact named Silicon Border continues, pollution tendencies for $\mathrm{NO}_{2}$ and $\mathrm{SO}_{2}$ will change for sure. Most of all because among the currently installed are the chemical, metallurgical, paper and food industries, considered as the ones that affects the environment the must.

\subsection{Environmental planning and air quality management: strategies for the improvement of air quality}

Urban planning needs to consider aspects like the following in order to face important challenges of the cities that have to do with air quality and the health of its population.

- Industry: joint land use planning with strategic environmental assessment; the implementation of norms in authorizing and monitoring of industry operation; publishing and providing communication to the general public about the characteristics of industrial emissions; promoting industries to join environmental certification programs; and discourage the setting of industries in the fields of electricity, metallurgic, chemical, paper and food, to reduce the participation of industries identified as those who generate considerable amounts of emissions and that are considered highly polluting.

- Agriculture: controlling and monitoring agricultural field burning; the application of agrochemical substances and pesticides in productive areas and the setting up of green buffer zones. 
- Material extraction sites: regulating and monitoring the emissions during their operation.

- Sanitary land fills: defining an adequate and timely site for disposing solid waste, hazardous waste, as well as their emissions.

- Transportation and traffic: promote through the regulation of land uses, a compact pattern of the city with higher population densities that tends to reduce distances between home and work. There should also be an increase in the primary traffic infrastructure and better pavement coverage. Provide incentives for an increase public transportation, with newer and more adequate units appropriate to local weather. Also, it is of outmost importance to regulate the vehicles in use, and the ones that are 10 years old or more; verify emissions and promote economic or fiscal incentives to substitute old vehicles.

- Public green areas: reduce the deficit of public parks and promote its contribution to improve air quality, through adequate species for the region.

- Energy: promote the quality of fuels used for transportation, but also the generation and use of alternative sources of energy for industrial, domestic and commercial use in order to reduce the burning of fossil fuels.

- Health and quality of life: systematic follow up of health problems related to respiratory diseases due to high pollution levels, along with a preventive program that provides information and guides the population to preserve good health.

- Policy and urban environmental standards: defining policy, as well as standards, that respond to the local situation are required in order to define and instrument strategies and programs oriented towards improving the present urban environmental problems.

- Production of environmental data: developing pressure and response indicators that can be complemented by the state indicators (present air quality conditions), providing information based on the monitoring systems and the emission inventories that influence the design of public policies to measure the performance of programs provided by other sectors.

- Information and communication: it is recommended that this is implemented so that the policies, programs, and actions are not only known by the government authorities who work in the design and implementation of strategies and successful programs for air quality improvement, but that the general public has the adequate and timely information about air quality and the atmosphere conditions when precautions must be taken. These aspects will contribute considerably in the promotion of environmental and cultural education.

- Environmental education: this is an important issue, as it can promote interest and awareness of the population about environmental problems. In a particular manner about the state and conditions that local air quality has. Due to the importance and magnitude of the issue, it is convenient not only to depend on the strategies implemented by the government. The educational sector needs to incorporate in its curriculum, subjects related with the environment and the perspective it presents for modern times. 


\section{Conclusion}

City planning must count with tools that help it make an environmental assessment not only of air quality, but also other resources to have influence over them. It is also necessary to stop thinking that air quality in the city, is only a responsibility of the ecological and energetic sectors, it also needs the participation of other sectors, like urban development, in which it would be necessary to develop suitable methodologies for the treatment of environmental aspects that improve the air quality of the cities.

\section{References}

[1] AQS-UABC, Database: pollutants $\mathrm{PM} 10, \mathrm{CO}, \mathrm{NO}_{2} \mathrm{SO}_{2}$, and $\mathrm{O}_{3}$, Technical research report: UABC, Mexicali, B.C., Mexico, 2006.

[2] XVIII Mexicali City Council and IMIP, Urban development programme for Mexicali, B.C. 2025.: Council of Mexicali, Mexico,2006.

[3] Gordillo, C. Personal communication 19 October 2006, Department of ecology of the city council of Mexicali, B.C.

[4] IIS-UABC and JUBC Assessment of integrated programme for the improvement of quality of life in the state of B.C. Technical research report, UABC: Mexicali, B.C., Mexico, 2006.

[5] Leitmann, J. Rapid urban environmental assessment. Lessons from cities in the developing world. Methodology and preliminary findings. Urban management programme. World bank: Washington, D.C. 1994.

[6] Mendoza, A., García, M. and Pardo, E., Air quality information catalogue for the Mexicali-Imperial Valley border region: Mexicali-Imperial Valley air quality modeling and monitoring programme in support of LASPAU's border ozone reduction and air quality improvement program. Draft final report LASPAU-ITM: Mexico, 2004

[7] Mitchell, G. Forecasting urban futures: a systems analytical perspective on the development of sustainable urban regions (Chapter 5). Exploring sustainable development: Geographical perspectives, ed. M. Purvis and A. Grainger, Earthscan: UK-USA, 2004.

[8] Paez, E. Personal communication 20 January 2007, City council institute of research and urban planning (IMIP).

[9] Rojas, R., Urban environment assessment: methodological proposal and application to a study case. Mexicali, Baja California. Doctoral thesis in urbanism, faculty of architecture, UNAM, Mexico D.F. 2000.

[10] SEMARNAP, Government of Baja California, Health department, city council of Mexicali Programme for air quality improvement in Mexicali 2000-2005. SEMARNAP, Mexico, 1999.

[11] SEMARNAP, Integrated system of regulation and environmental management on industries in Mexico. SEMARNAP,-INE: Mexico, 1997

[12] United Nations Environment Programme (UNEP) Urban outdoor pollution, in global environmental outlook year book 2006. Online.

[13] http://www.unep.org/geo/yearbook/yb2006/057.asp 